\title{
Job-Field Underemployment and Career Satisfaction: A Relationship of Cause and Effect
}

\author{
Sharon More ${ }^{1} \&$ Tova Rosenbloom ${ }^{2}$ \\ ${ }^{1}$ Logistic Department, Sapir Academic College, Israel \\ ${ }^{2}$ Department of Management, Bar Ilan University, Israel \\ Correspondence: Sharon More, Logistic Department, Sapir Academic College, Israel. E-mail: \\ sharonmore1986@gmail.com
}

Received: August 13, 2020

Accepted: September 4, 2020

Online Published: September 21, 2020

doi:10.5539/ijbm.v15n10p82

URL: https://doi.org/10.5539/ijbm.v15n10p82

\begin{abstract}
The current article deals with the interesting phenomenon of mismatch between an academic graduate's field of education and their field of occupation (a phenomenon known in the literature as horizontal-mismatch or job-field underemployment), and its impact on the individual's career satisfaction. Some studies regarding the broader phenomenon of underemployment suggest that graduates might temporarily accept an underemployed job in order to avoid unemployment and obtain some work experience, but even though most of the relatively scarce articles on the subject suggest it is usually an involuntary phenomenon, almost none of them specifically focus on the case of job-field underemployment.

310 Israeli academics with almost-equal gender representation participated in this study. A statistically significant negative correlation has been found, according to which, the greater an individuals' level of job-field underemployment, the lower their career satisfaction level. The main conclusion of the present study is that the individuals' quality of job-field fit appears to be a very significant component in their career perception: The individual, being rational, will invest in a specific field of education in order to integrate into the labor market accordingly. Therefore, this phenomenon is not desirable for the individual, and it requires more informed career planning by the individual in order to avoid experiencing this phenomenon in the first place. At the macro-economic level, this requires better labor-market adjustments between the supply of labor and the demand for jobs.
\end{abstract}

Keywords: economics of education, labor underutilization, underemployment

\section{Introduction}

The phenomenon of the inefficient allocation or under-allocation of resources in general, and of the human capital resource in particular, has been a common phenomenon in recent years in the labor economics of the economies of Western, developed and industrialized countries (Morck, Yavuz, \& Yeung, 2011). One of the implications of this phenomenon on the economy in the macro level is the formation of surpluses in the supply of resources (and of the human capital resource in particular) in certain fields, at the expense of a shortage in the supply of skilled productive elements in others. Such a business environment in the economy may negatively influence growth (Gomes, 2015) and indirectly - low work productivity rates, as well. (Eckstein, Lifschitz \& Trilnick, 2016).

One of the most common occupational phenomena in the Western world today, in the context of the aforementioned inefficient allocation of employees - albeit on the micro level - is the phenomenon of how well an academic individual's field of education and their field of employment are matched (job-field underemployment) and its general implications regarding their income levels, their degree of job satisfaction and their myriad occupational choices throughout their career (Nordin, Persson, \& Rooth, 2010; Ordine \& Rose, 2011). The purpose of the current study is to innovate and delve deeper into the implications of an individual's experience of job-field underemployment on their degree of career satisfaction, all the while differentiating between the objective dimension of job-field underemployment and its subjective-perceived dimension. Thus, this article's contribution to research is expressed by estimating whether and to what extent this phenomenon is prevalent and voluntary, or whether it is typically an occupational reality after the fact, and involuntary. 


\section{Theoretical Background}

\subsection{Job-Field Underemployment}

Mismatch in the education-occupation field plane is a specific phenomenon that falls under the umbrella of the general term "underemployment". The term in question consolidates several phenomena of employment involving underutilization and lack of correspondence/compatibility between the characteristics of jobs throughout an individual's career and the characteristics of that individual (Thompson, Shea, Sikora, Perrewe, \& Ferris, 2013): Their level of education (for example, over-education), their field of education, their skills and occupational experience (over-qualification), their potential earning ability (underpayment) and so forth.

The phenomenon of a mismatch between the field of an academic individual's education and their field of occupation is referred to in the literature as "job-field underemployment" (Burke, 1997; McKee-Ryan \& Harvey, 2011), or "horizontal mismatch" (Nordin et al., 2010). Out of all of the above phenomena that fall under the umbrella of "underemployment", job-field underemployment receives relatively little reference in relevant research literature, and this is particularly true concerning the scope of the phenomenon and its implications for the individual. In his groundbreaking research on the phenomenon of job-field underemployment, Robst (2007, p. 398) reviewed a few principal causes for the selection of fields of education amidst academic individuals, such as: projected salary levels, current patterns of workforce participation, uncertainty level and the chances to graduate successfully. One of the conclusions that emerged from the research by Nordin et al. (2010) is that job-field underemployment is typically involuntary, which may indicate that the original intent of the individual (to integrate into the economy) was unfulfilled. Robst (2007, p. 406) found in his study that the phenomenon of objective job-field underemployment is common, showing that $45 \%$ of the participants in his study were found to be underemployed.

However, information concerning the scope of the job-field underemployment phenomenon amidst academics in the Israeli economy remains relatively scarce, with one of the single few recent studies on this subject (OECD, 2017 ) indicating that approximately $36.5 \%$ of academics experience objective job-field underemployment in the local economy: the highest degree of underemployment was found in the humanities, which also include languages and art (70\%) and the lowest degree was found in the social studies, which also include law and business $(24 \%)$. In the fields of engineering and education, adequate employment of approximately $35 \%$ was found, and in the field of services, which includes, for instance, tourism studies $-60 \%$ of the graduates were not employed in their field. It has further been found that the phenomenon itself is rather widespread amidst Israeli academics, where the rate of Bachelor's Degree graduates that are not employed in a job that matches their field of education, by objective segmentation, stands at approximately $29 \%$, and the salary of the underemployed is approximately $11 \%$ lower than the salary of their cohorts who are employed in a job that matches their academic education (Romanov, Tur-Sinai, \& Eizman, 2017). Moreover, a new study by the Bank of Israel (Lipiner, Rosenfeld \& Zussman, 2020) on this subject indicated that in the entire Israeli economy, mismatch between the fields of education and occupation correlates with salary that is $5 \%-6 \%$ lower than that of those who do not experience such mismatch, among both women and men.

\subsection{Subjective Job-Field Underemployment}

In studies conducted on the subjects of interpersonal interaction and organizational research, it has been found that generally, the manner in which an individual perceives information is more important than its objective characteristics for predicting their behavior and understanding their decision-making processes. (Boyd, Dess, \& Rasheed, 1993). The term "perceived underemployment" describes a state of mismatch between an individual's human capital attributes (personal skills, field of education and occupational experience) and a particular job, in accordance with the individual's subjective perception (Watt \& Hargis, 2010).

Studies have found that objective and subjective underemployment are positively linked - That is to say, employees who objectively experience some form of underemployment tend to usually perceive themselves as underemployed at that specific point of time in their career. (McKee-Ryan, Virick, Prussia, Harvey \& Lilly, 2009). Robst (2007), accordingly, also focused on the subjective aspect of job-field underemployment - and examined the differences between individuals in various categories of mismatch regarding assorted variations in their salary levels. Most studies focused on the subjective aspect of the job-field unemployment phenomenon or made a distinction between it and its objective aspect (Chevalier, 2003; Green \& Zhu, 2010). Accordingly, this current work also examined both the objective and subjective aspects of job-field underemployment, pertaining to the effect of this phenomenon on further decision-making in an individual's career (career outcomes).

In his groundbreaking review of this subject, Feldman (1996) proposed, especially as a recommendation for further research, several general antecedents for the phenomenon of underemployment, particularly in the micro 
level and in the individual level, such as economic factors, job characteristics, career history, job search methods and demographic characteristics. However, the subject of the implications of underemployment in general - and job-field underemployment in particular - on the changes in one's career, particularly as they are reflected by the degree of their satisfaction with their career, are relatively unexplored territory in the literature. Figure 1 schematically presents, in accordance with Feldman's (1996) review, the main factors (antecedents) proposed as predictors of underemployment (economic factors, job characteristics, career history, job-search strategies and demographic characteristics) as well as the main factors which may arise out of this situation (the implications). Further on in this work, as said, the subject of the implications of job-field underemployment regarding the management and planning of an individual's career, focusing on the career satisfaction variable, shall be developed.

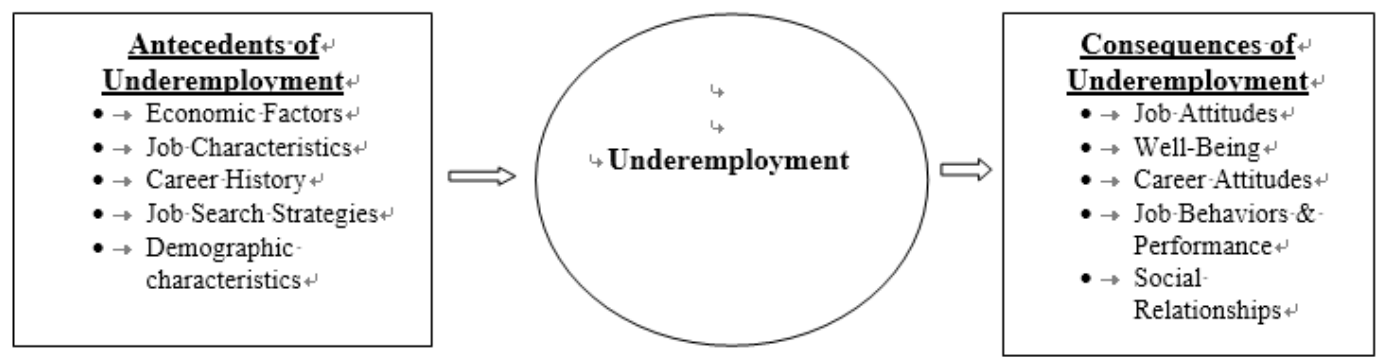

Figure 1. Antecedents and consequences of underemployment (Feldman, 1996)

\subsection{Career Satisfaction}

Career satisfaction refers to an individuals' subjective perception concerning their success throughout their career (Stumpf \& Taymon, 2012). This term differs from objective career success, which is expressed more in terms of actual advancement (hierarchical or horizontal) in status / rank at work, or in salary, etc. (Ng, Eby, Sorensen, \& Feldman, 2005). Occupational psychology attributes positive work outcomes to the degree of match and similarity between the person and their occupation, and the primary measures which it focuses on are career commitment, job satisfaction and more (Duckworth, Steen, \& Seligman, 2005). Starting with the initial theories regarding the above-mentioned person-job fit, it has been estimated that the greater the congruence between the characteristics of an individual and the characteristics of their occupation - the greater their job satisfaction should be, with further studies emphasizing the contribution of the congruence between occupational characteristics and the occupational environment to career satisfaction (Holland, 1997).

Literature does exist concerning the phenomenon of general underemployment, and its potential effect on an individual's general job attitudes, but it is relatively generalized: the focus of research on job loss has changed over time from mere reemployment to reemployment quality, a change which reflects the reality in which integration into a job may not lead a laid-off employee back to the desired equilibrium (as far as they are concerned) in the job market (McKee-Ryan et al., 2009, p. 565). Studies have found that employees with low reemployment quality continued to face the effects of job loss at a similar level to employees that remained unemployed: under the belief that such a disruption of their career caused by layoff, it has been claimed that this creates a gap between their current occupational status and their desired status, leading to a feeling of inequality and a desire to change their occupational status (McKee-Ryan et al., 2009).

Subjective underemployment reflects the same gap mentioned above (McKee-Ryan et al., 2009): employees experiencing underemployment wish for, and believe themselves deserving of, a better job (possibly in terms of job-field match as well) and perceive themselves as overqualified for their position. Job satisfaction constitutes an important job attitude for the individual, reflecting the attainment of their desired (occupational) equilibrium and including a cognitive, emotional and appreciative response to their position (Leana, Feldman \& Tan, 1998). Therefore, subjective perceptions of mismatch between an individual's skills and work at a job that does not meet their expectations, may be related to a reduced sense of career satisfaction (McKee-Ryan et al., 2009, p. 566).

Out of cross-referencing job characteristics and satisfaction data amidst Israeli Bachelor's Degree graduates (Central Bureau of Statistics, 2010), it emerges that those graduates whose jobs were related to their fields of education expressed a slightly higher degree of satisfaction than that which was expressed by graduates whose 
job is not related to their field of education: The differences were found to be statistically significant, but no conclusion could be drawn regarding the direction of the causality between the degree of educational satisfaction and success in the job market out of this finding. An additional study which re-examined the attributes of occupational integration of Israeli Bachelor's Degree graduates in the field of education (Central Bureau of Statistics, 2011), a higher degree of satisfaction was found amidst graduates with the occupational intent of teaching after graduation, than amidst graduates who noted "acquiring high education" as the primary motivation for their studies.

A follow-up study revealed that $93 \%$ of the graduates whose work was highly or partially related to their studies, expressed satisfaction concerning their degree of interest in their work (Central Bureau of Statistics, 2014): The rates of employees that were satisfied with the degree of interest in their work and the possibilities for promotion in their work, where it was unrelated to their field of education - were substantially lower ( $79 \%$ and $50 \%$ accordingly), than these rates amidst those whose work was related to their studies.

As aforementioned, underemployment as per its general definition has been consistently linked in studies through the years with poorer individual job attitudes, such as job satisfaction, organizational commitment, turnover intentions etc. (Khan \& Morrow, 1991). Studies (Ren, Bolino, Shaffer, \& Kraimer, 2013) suggested that perceived underemployment should be negatively linked with individual satisfaction regarding the overall course of their career (career satisfaction), but their hypothesis was not reinforced. In their study of 88 male and female Bachelor's Degree graduates, Littman-Ovadia and Davidovich (2008) hypothesized (inter alia) that there is a positive link between an individual's educational-occupational fit and their job satisfaction, job success, career commitment and general personal welfare. Their findings revealed that job satisfaction, the sense of job success and overall personal welfare - are explained through daily use of the individual's personal strong points, and the degree of adequacy of job-field employment did not provide a significant addition to these explanations.

As mentioned above, it is reasonable to assume that an individual, being rational, would acquire a specific field of education with a rather clear purpose of working in this field throughout their career (Dar \& Getz, 2007), and thus perceived (subjective) job-field underemployment may be interpreted as a career barrier. It is also possible, then, to assume that subjective job-field underemployment shall negatively impact the individual's satisfaction concerning the course of their career. Therefore, the innovation of this current article is examining in what way perceived job-field underemployment may be negatively linked with an individual's degree of career satisfaction. As a result, the next paragraphs shall discuss an additional potential implication of an individual experiencing job-

field underemployment - their organizational citizenship behavior. Therefore, as the purpose of this article is to innovate and delve deeper into the implications of an individual experiencing job-field underemployment on their degree of career satisfaction, all the while making a distinction between the objective and subjective dimensions of the job-field underemployment phenomenon - the research question that follows is whether, and in what manner, does job-field underemployment affect an individual's degree of career satisfaction.

\subsection{Study Hypothesis}

The degree of an individual's (subjective) job-field underemployment and their degree of career satisfaction shall be negatively linked, thus the higher the degree of job-field underemployment, the lower the degree of career satisfaction.

\section{Method}

\subsection{Participants}

Table 1 specifies the demographic-general and socioeconomic background characteristics of the study participants. These were voluntarily and anonymously recruited, both by means of physically distributing and collecting a questionnaire and of an online questionnaire that is entirely identical to the physical one (21 participants completed the physical questionnaire, and no differences have been found between the findings of the online questionnaire and the physical questionnaire). Online participants have been recruited over several platforms and through personal contact, mostly via alumni websites (academic study graduates, such as universities' alumni), professional-social networks (such as LinkedIn), professional forums, authors' colleagues, et cetera. Participants were given an explanation that this was a "work to research career decision-making moves under the framework of doctorate studies in the Department of Management, the Bar-Ilan University's Faculty of Social Sciences". 
Table 1. Participants' demographic and socioeconomic background characteristics

\begin{tabular}{lcc}
\hline Variables and values & Frequency & Distribution (\%) \\
\hline Gender & & \\
Females & 157 & 50.64 \\
Males & 153 & 49.36
\end{tabular}

\section{Education level}

$\begin{array}{lll}\text { Bachelor's degree } & 172 & 55.5 \\ \text { Master's degree } & 132 & 42.25 \\ \text { Ph.D. } & 7 & 2.25\end{array}$

\section{Job-field Underemployment}

Adequately employed

$229 \quad 74$

Underemployed

$81 \quad 26$

\section{Marital status}

$\begin{array}{lll}\text { Singles } & 97 & 31.3 \\ \text { Married } & 191 & 61.3 \\ \text { Divorced } & 19 & 6.4 \\ \text { Widows } & 13 & 1\end{array}$

\section{Income level}

$\begin{array}{lll}\text { Significantly below average } & 39 & 13 \\ \text { Slightly below average } & 28 & 9.4 \\ \text { Quite equal to the average } & 39 & 13 \\ \text { Slightly above average } & 84 & 28.1 \\ \text { Significantly above average } & 109 & 36.5\end{array}$

\section{Education fields}

$\begin{array}{lll}\text { Art professions } & 8 & 2.6 \\ \text { Engineering } & 43 & 13.9 \\ \text { Health Science } & 3 & 1 \\ \text { Life science } & 13 & 4.2 \\ \text { Jewish Studies } & 2 & 0.65 \\ \text { Humanities } & 14 & 4.5 \\ \text { Exact Sciences } & 30 & 9.5 \\ \text { Law studies } & 10 & 3.15 \\ \text { Medicine } & 3 & 1 \\ \text { Social Sciences } & 184 & 59.5\end{array}$

Additionally, Table 2 also presents the descriptive statistics of the principal background variables of the rational scale, to understand the statistical analyses appearing later in the "findings" chapter:

Table 2. Descriptive statistics of continuous background variables

\begin{tabular}{lllllll}
\hline & $\begin{array}{l}\text { Job-field } \\
\text { underemployment }\end{array}$ & Seniority & Career history & Unemployment & Income level & Age \\
\hline Average & 2.69 & 9.79 & .47 & .30 & 3.66 & 36 \\
Standard deviation & 1.08 & 6.97 & 1.01 & .66 & 1.39 & 7.35 \\
Various & 1.17 & 48.67 & 1.03 & .43 & 1.93 & 54.12 \\
Range & 4 & 50 & 12 & 5 & 4 & 49 \\
\hline
\end{tabular}




\subsection{Instruments}

The study made use of the following questionnaires in order to study the principal variables, other than job-field underemployment, which the research literature on this subject indicates may primarily serve as predictors of the degree of an individual's career satisfaction, particularly amidst individuals experiencing underemployment (Ren et al., 2013; Verbruggen, van Emmerik, Van Gils, Meng \& de Grip, 2015):

Subjective job-field underemployment. This variable was based on the original underemployment variable measurement questionnaire composed regarding this subject (Bolino \& Feldman, 2000). This study instrument measures the degree in which tasks in the participants' jobs are perceived among them as ones that make the most optimal use of their education, experience, training, skills and competencies. The questionnaire is a five-item, five-point Likert scale, with 1 representing "Very slightly agree" and 5 representing "Very highly agree", thus the higher the score, the more the individual is experiencing subjective job-field underemployment. Cronbach's alpha for this instrument in the original article was found to be 0.9 (Bolino \& Feldman, 2000), and following its findings, the sixth item of the original questionnaire has been removed. To normalize the distribution of the variable, its values were transformed by raising to the 0.36 th power, which indeed aided in the distribution of the variable.

The reliability of the questionnaire in this current study is $\alpha=0.876$, with the questionnaire being validated by a Mann-Whitney test for examining the statistical significance of the differences between those objectively underemployed and adequately-employed in the job-field sense, and the mean of their degrees of subjective job-field underemployment. As noted in Table 3, it has been found that the differences between the groups are statistically significant, thus the mean rating of the degree of subjective job-field underemployment amidst those objectively underemployed is higher than the mean rating of the degree of subjective job-field underemployment amidst those objectively adequately-employed.

Table 3. Mann-Whitney test results for comparison between adequately employed and underemployed

\begin{tabular}{llllll}
\hline & $\begin{array}{l}\text { Adequately-employed } \\
(\mathrm{n}=230)\end{array}$ & $\begin{array}{l}\text { Underemployed } \\
(\mathrm{n}=80)\end{array}$ & $\begin{array}{l}\text { Standard deviation in } \\
\text { the variable }\end{array}$ & $W$ value & $Z$ value \\
\hline Dependent variable & $M$ & $M$ & $S . D$. & 28346 & $-10.764^{* *}$ \\
\hline $\begin{array}{l}\text { Subjective job-field } \\
\text { underemployment }\end{array}$ & 123.21 & 248.24 & 1.081 & & \\
\hline Note. ${ }^{* *} p<.01$. & & & & & \\
\hline
\end{tabular}

Objective job-field underemployment has been measured via a comparative cross-check between the participants' field of education and their field of occupation and their jobs, in a similar manner to the dichotomous measurement in additional studies on this subject (Robst, 2007). The classification of patients into the objectively underemployed/objectively adequately-employed categories was performed, inter alia, by a professional forum consisting of several different arbiters (an inter-rater reliability process, after a fashion), among whom were the authors and professionals in the field of human resource recruitment and management in organizations.

Career satisfaction. This variable measured using the original questionnaire for measuring an individual's career satisfaction (Greenhaus, Parasuraman, \& Wormley, 1990). This questionnaire is composed of five statements in a five-point scale, with 1 representing "To a very small extent" and 5 representing "To a very great extent", thus the higher the score, the higher the individual's career satisfaction is. The Cronbach's alpha coefficient for this questionnaire is identical to the reliability found in previous studies on this subject (0.88), with Cronbach's alpha coefficient for the questionnaire in this current study found to be 0.916 .

Layoff history. The variable reflecting the number of incidents in which an individual experienced involuntary departure from a job/organization throughout their career since the completion of their Bachelor's Degree studies, measured in the study instruments via the item "Out of the jobs you were employed in since the completion of your Bachelor's Degree, how many have you been laid off from?"

Unemployment duration. The variable reflecting the cumulative duration of time in which the individual experienced involuntary unemployment throughout their career, measured in the study instruments via the item "What is the estimated cumulative duration of time (in years) in which you've experienced involuntary unemployment throughout your career, since the completion of your Bachelor's Degree studies and until today?". 
The quantitative variable received denoted the duration of time (in years) in which the participants experienced unemployment throughout their career.

Income level. An ordinal-scale variable with five levels, measured relative to the average monthly salary for a salaried employee's job in the economy at the point in time the study questionnaire was completed.

Turnover intentions. The variable has been measured using three items (Yucel, 2012), based on the extended five-item questionnaire (by Price, 1997), the responses for which range between 1, representing "To a very small extent", and 5, representing "To a very great extent". Each item denotes the participant's likelihood to leave the organization in the near or far future. The average of the three items constituted the subject's general score concerning their turnover intentions, with a higher score reflecting a greater intention to leave the job. The Cronbach's alpha reliability coefficient found for the said translated questionnaire was 0.71 , while the Cronbach's alpha coefficient of the questionnaire in this current study was found to be 0.93 .

Organizational citizenship behavior. The variable is measured via the Organizational Citizenship Behavior questionnaire (Van Dyne \& LePine, 1998). This questionnaire contains seven reporting items on a seven-point scale, with 1 representing "To a very small extent" and 7 representing "To a very great extent", thus, the higher the score, the more the individual demonstrates organizational citizenship behavior. The Cronbach's alpha coefficient of the questionnaire in this current study was found to be 0.928 .

Demographic and general variables. The study instruments also included general demographic background variables such as gender, age, marital status, the individual's seniority in the job market since the completion of their Bachelor's Degree studies, education level, job scope (the overwhelming majority of the participants worked full-time, as opposed to a few who worked part-time), employment type (the overwhelming majority of participants are salaried employees, versus a very small number of self-employed participants and participants who are concurrently self-employed and salaried employees), etc.

\subsection{Procedure}

Initially, a preliminary pretest was conducted for the study instruments, in which several consulting participants took part, among whom was a specialist consultant on the subject of research methods and statistics at the academic institution under which the research work was conducted. Each participant subjectively reported the duration of time it took them to complete the study instrument, the convenience of its interface and the clarity of its language in terms of syntax and grammar, in order to draw conclusions ahead of the pilot phase. After the preliminary pretest, a pilot of the study instruments was conducted with ten additional participants who were recruited out of the authors' professional circle, this in order to continue examining comments from additional perspectives, and also in order to continue examining whether there is a relative overabundance of variables which may allegedly make it more difficult for the study to attain reliable outcomes, and in which ways. At the end of this process, these preliminary participants were naturally included among the rest of the final study's participants.

Most participants were recruited through the author's initiative and personal contact online and via several platforms, mostly via alumni websites (academic study graduates, such as academic institution alumni), professional-social networks (such as LinkedIn, for example), professional forums, colleagues from the authors' work world, et cetera. The process of recruiting participants took approximately one year while, naturally, meeting the requirements of voluntariness, informed consent, anonymity and discreetness.

\subsection{Statistical Processing}

Under the framework of the study model, the hypothesis of the relationship between the variables of "subjective job-field underemployment" and "career satisfaction" was examined via hierarchical linear (stepwise) regression in four steps, which examined all variables predictive of an individual's degree of career satisfaction.

In accordance with the stepwise method, the order of the objective statistical significance of predictors determines the order in which variables are entered into the model equation. That is to say, the output of the regression analysis presents predictors arranged in the order of their significance pertaining to their relevant contribution to explaining the dependent variable, so the most explanatory variable is the first in line, and the non-explanatory variables are taken out of the model equation.

\section{Findings}

Out of an observation of the findings of the regression presented in Table 4, it emerges that a statistically significant regression has been obtained $[\mathrm{F}(4,294)=54.088, \mathrm{p}<.001, \mathrm{R}=0.651]$ and the percentage of explained variance $\left(R^{2}\right)$ is $42.4 \%$. The values of standardized regression coefficients $(\beta)$ indicate that the contribution of the 
four following variables: subjective job-field underemployment, turnover intentions, income level and organizational citizenship behavior (OCB) to the prediction of career satisfaction is statistically significant. In the first step, the organizational citizenship behavior variable explained $19.6 \%$ of the general variance; in the second step, the income level variable contributed an additional $12.7 \%$ to the explanation of the variance from the first step; In the third step, the turnover intentions variable contributed an additional $5.9 \%$, and in the fourth (and final) step, the subjective job-field underemployment variable contributed the remaining $4.2 \%$ to the model's variance.

Based on the standardized regression coefficients $(\beta)$, it may be observed that a positive correlation was found between each of the "organizational citizenship behavior" and "income level" variables and the dependent variable (career satisfaction) - that is to say, the higher the level of organizational citizenship behavior the individual experiences and/or the higher their income level, the higher their career satisfaction. In addition, a negative correlation was found between each of the "turnover intention" and "subjective job-field underemployment" variables and the dependent variable - that is to say, the higher the individual's turnover intentions, and/or the higher their degree of perceived job-field underemployment (each individually), the lower their career satisfaction. Additionally, the assumptions of the model have been met, with a linear relationship found between the dependent and independent variables, the rest of the model demonstrated a normal distribution and also, the assumption of homoscedasticity is met (the variance of random disturbances in the model was found to be regular, with the correlation between the error and the predicted value in the study model being zero, and the observations were found to be relatively uniformly distributed around the regression line).

Table 4. Findings of the model (hierarchical linear regression to predict career satisfaction level)

\begin{tabular}{llll}
\hline Variable & $\beta$ & S.E. $B$ & $B$ \\
\hline Step 1 & & & \\
OCB & $.433^{* *}$ & 0.038 & 0.320 \\
Step 2 & & \\
OCB & $.378^{* *}$ & 0.035 & 0.274 \\
income_level & $.362^{* *}$ & 0.032 & 0.240 \\
Step 3 & & & \\
OCB & $.310^{* *}$ & 0.035 & 0.224 \\
Income_level & $.313^{* *}$ & 0.031 & 0.208 \\
Turnover_intentions & $-.260^{*}$ & 0.035 & -0.184 \\
Step 4 & & & \\
OCB & $.263^{* *}$ & 0.035 & 0.191 \\
Income_level & $.273^{* *}$ & 0.031 & 0.181 \\
Turnover_intentions & $-.222^{* *}$ & 0.034 & -0.160 \\
Tsubjective_JFU & $-.223^{* *}$ & 0.211 & -0.975 \\
\hline
\end{tabular}

Note. $R^{2}=.193$ for Step $1 ; R^{2}=.303$ for Step $2 ; R^{2}=.382$ for Step $3 ; R^{2}=.424$ for Step 4;

\section{Discussion}

This study examined the implications of an academic individual experiencing job-field underemployment on their continued career management and planning in terms of career satisfaction, which constitutes both the innovation this study brings and its unique contribution to the vast body of literature in this field. The theoretical framework of this current study is an expansion of Feldman (1996)'s model in which several possible "products" of the individual experiencing job-field underemployment are discussed. Complex statistical modeling was conducted to examine the study hypothesis:

The study hypothesis that the subjective job-field underemployment variable shall be a statistically significant predictor of career satisfaction has been reinforced: the results of the model's linear regression analysis yielded negative correlation between the subjective job-field underemployment and career satisfaction variables, in such a way that the higher the individual's degree of perceived job-field underemployment, the lower their career satisfaction. This finding aligns with the findings of studies on the subject of underemployment as per its general definition, consistently associated in research over the years with less-positive individual job atittudes, and inter alia, job satisfaction (Khan \& Morrow, 1991). Again, as mentioned above, there is no dispute that an individual, being rational, would acquire a specific field of education with a fairly clear intention of working in this field 
during their career in the first place (Dar \& Getz, 2007) and treat the investment in their human capital almost in the same way as any investment in their physical capital or any other financial capital. Therefore, assuming an adequate job-field fit is an important goal in the individual's career, it would be natural and reasonable to assume that job-field underemployment may negatively affect their satisfaction from the way their career has developed, at the very least in the aspect of the fit between their field of occupation and field of education. That is to say, it is possible that job-field underemployment may be interpreted by an individual as a breach of a "psychological contract", after a fashion, on behalf of the job market - a "contract" which engrosses the individual's expectation to integrate into the economy in a field of occupation and in a job that correspond with their field of education.

Although several other variables were found under the framework of the study model to be predictors of career satisfaction to no lesser extent than job-field underemployment, they do not constitute any innovation to research in the manner job-field underemployment as a predictive variable does: for example, the model did find a positive correlation between income level and career satisfaction, but this finding is substantially less surprising as the literature, since the very beginning, found a statistically significant link between the employee's job satisfaction and their salary levels (Rubin, 2010): previous studies concerning job satisfaction already emphasized the central importance of compensation in determining the employees' job attitudes, and thus their satisfaction with their salaries was found to be one of the most important aspects of job satisfaction, due to the high rating of the subject of salary in the scale of the employee's needs from their workplace (David, 2006). Additionally, in regard to the negative correlation found between turnover intentions and career satisfaction, many studies have already discussed the relationship between an individual's satisfaction (of their career/organization) and their tendency for turnover (Leny, 2009): even though some found a direct link between satisfaction with the organization and the tendency for turnover (that is to say, the degree of identifying with the organization as an inhibiting/expediting factor for leaving the organization), many studies on the subject yet point to a reverse relationship according to which the individual's degree of satisfaction is the primary and important variable - explaining their tendencies for leaving an organization/job/occupation (Yucel, 2012). This, as job satisfaction by nature is negatively identified with the degree of the employee's withdrawal behavior and their commitment to the organization (Nathan, 2009, p. 94).

This current article has several limitations. First, even though sampling was conducted randomly, most participants were graduates of degrees in the social sciences and the humanities (approximately $60 \%$ ) and the rest were graduates in the field of life sciences, exact sciences, assorted engineering fields, et cetera. Additionally, only $26 \%$ of all participants in this current study were found to be objectively job-field underemployed, but this may constitute a finding of its own right - that is to say, it is possible that this is the principal and actual trend in the Israeli economy in practice, where individuals in the Israeli economy tend to eventually converge over time and throughout their careers towards fields of occupation that are relevant to their field of education, even if they experience temporary "bumps" at certain points during their careers in the form of jobs in fields that do not correspond with their field of education. Thus, it is possible that being underemployed, at least objectively, is a temporary phenomenon in an individual's career.

Additionally, the study was based, for the most part, on self-reporting by participants, keeping in mind the certain degree of problematicness inherent in this. However, the mandatory ethical principles of discreetness and anonymity of the subject participants, necessarily and for lack of any other options, had to come at the expense of possible cross-referencing of the participants' reports with corresponding reports from their work world (reports by colleagues/managers etc. concerning the participants while responding to the questionnaires which the participants answered, official salary data, documented unemployment durations etc.). For lack of other options, it was impossible to obtain further objective data.

The unique contribution of this current article rests with the scientific innovations inherent to which: it may be possible to conclude from the reinforcement of the study hypothesis that as far as an individual is concerned job-field underemployment is, in practice, an involuntary phenomenon to begin with: after all, it has been found that the higher an individual's perceived degree of job-field underemployment, the lower their degree of career satisfaction. Therefore, if being underemployed has a negative effect on their career satisfaction, it is highly reasonable to assume that an individual's job-field underemployment would be, in most cases, unplanned and likely involuntary - an occupation reality after the fact. This is exactly the case with most of the other phenomena included under the "underemployment" umbrella term (McKee-Ryan \& Harvey, 2011), and stands in contrast to the approach according to which job-field underemployment may, in certain cases, be considered voluntary and initiated by the individual, due to changes in the individual's information, preferences and constraints (Nordin et al., 2010).

An additional innovation of this current article is the development of the questionnaire for measuring subjective 
job-field underemployment, which was found to be reliable and validated accordingly. This tool constitutes a significant pioneering innovation in the field and may greatly aid future studies in this field. The substantial innovations of the questionnaires are expressed in several manners: (a) being a specific measure of the variable of the job-field underemployment sub-phenomenon, unlike the classic questionnaire which measures the underemployment "super-phenomenon", with all the sub-phenomena it encompasses (Bolino \& Feldman, 2000). (b) being relatively avant-garde in measuring the job-field underemployment phenomenon as a continuous variable rather than a nominal-scale variable (see Burke, 1997). Using a continuous variable permits use of a broader supply of parametric statistical tests. Additionally, (c) the questionnaire subjectively measures the perceived level of underemployment, in parallel to the objective job-field unemployment questionnaire that already exists under the framework of the study instruments. This, while previous studies did not examine the objective and subjective variables within the framework of the same study. Additionally, the validation of measuring the variable using both questionnaires constitutes a research innovation of its own right in this field.

This article has practical implications, and its findings indicate the crucialness of the individual making an informed decision about the choice of field of education and the importance of a preliminary market-analysis of job availability in the field of education they wish to acquire, prior to acquiring said education. While in most cases it is indeed difficult to predict the condition of the market in advance, as one of an individual's main considerations when picking a field of education is the current relevant job availability, whereas Bachelor's Degree studies usually take at least 3-4 years. This creates a shortage of information for an individual, which may affect present preferences in acquiring education. However, a comprehensive examination of the market should greatly benefit the individual in the process of making an informed decision concerning investment in their human capital (in terms of satisfactory fields of education), just as it is with the process of examining the worthwhileness of any financial and/or physical investment in general, in an attempt to reach optimal and high-quality integration into the economy at the end of the period of studies, to the greatest extent possible.

\section{Conclusion}

In summary, the findings of the current study emphasize the crucialness of the individuals making an informed decision regarding the choice of field of education and the importance of a preliminary market analysis concerning job availability in the field of education they seek, prior to acquiring the education. That is to say, this study emphasizes the importance of choosing a field of education for the outline of the future career. Choosing an academic educational field is a choice with a substantial, long-term effect: the chosen field of education directly influences the skills that the individual shall acquire throughout their studies and would later be utilized by them, and by their employers, in the job market (Kril, Geva and Aloni, 2016) and determine the course of their future career to a great extent. It has also been found in this study that experiencing job-field underemployment negatively affects an individual's career satisfaction over time, which may possibly imply that experiencing job-field underemployment, in and of itself, is typically involuntary and certainly not planned. The study of possible circumstances which may serve as 'generators' of objective job-field underemployment, after a fashion (such as macro-economic circumstances), as well as the study of the implications of additional possible outcomes of job-field underemployment (beyond career satisfaction) in the macro-economic level, may greatly aid in further understanding the scope of this phenomenon in-depth, and ways for addressing it - in both the micro and macro levels.

\section{References}

Bolino, M. C., \& Feldman, D. C. (2000). The antecedents and consequences of underemployment among expatriates. Journal of Organizational Behavior, $21, \quad 889-911$. https://doi.org/10.1002/1099-1379(200012)21:8<889:AID-JOB60>3.0.CO;2-G

Boyd, B. K., Dess, G. G., \& Rasheed, A. M. A. (1993). Divergence between archival and perceptual measures of the environment: Causes and consequences. Academy of Management Review, 18(2), 204-226. https://doi.org/10.5465/amr.1993.3997514

Burke, R. J. (1997). Correlates of under-employment among recent business school graduates. International Journal of Manpower, 18, 627-635. https://doi.org/10.1108/01437729710186455

Central Bureau of Statistics (2010). Recipients of First Degrees from Institutions of Higher Education: Satisfaction with Studies, Employment and Continuation of Studies. Jerusalem: Central Bureau of Statistics.

Central Bureau of Statistics (2014). Continuation of Studies and Work Five Years After Receiving A First-Degree Graduates of Universities and Academic Colleges in the 2005/06 Cohort. Jerusalem: Central Bureau of Statistics. 
Central Bureau of Statistics. (2011). Recipients of a B.Ed. Degree from Academic Colleges of Educations: Satisfaction with Studies, Employment, and Continuation of Studies 5773. Jerusalem: Central Bureau of Statistics.

Chevalier, A. (2003). Measuring over-education. Economica, $\quad$ 70, 509-531. https://doi.org/10.1111/1468-0335.t01-1-00296

Dar, Y., \& Getz, S. (2007). Learning ability, socioeconomic status and student placement for undergraduate studies in Israel. Higher Education, 54, 41-60. https://doi.org/10.1007/s10734-006-9045-1

David, G. (2006). The relationship between perceived organizational support and perceptions concerning salary and job satisfaction and normative commitment. (Department of Psychology Master's Thesis), Tel Aviv University, Israel.

Duckworth, A. L., Steen, T. A., \& Seligman, M. E. P. (2005). Positive psychology in clinical practice. Annual Review of Clinical Psychology, 1, 629-651. https://doi.org/10.1146/annurev.clinpsy.1.102803.144154

Eckstein, Z., T., Lifschitz, A., \& Trilnick, T. (2016). Technological and Professional Higher Education. Aaron Institute for Economic Policy, the Interdisciplinary Center Herzliya.

Feldman, D. C. (1996). The nature, antecedents and consequences of underemployment. Journal of Management, 22, 385-407. https://doi.org/10.1177/014920639602200302

Gomes, O. (2015). Optimal resource allocation in a representative investor economy. Economic Modelling, 50, 72-84. https://doi.org/10.1016/j.econmod.2015.06.008

Green, F., \& Zhu, L. (2010). Overqualification, job dissatisfaction and increasing dispersion in the returns to graduate education. Oxford Economic Papers, 62, 740-763. https://doi.org/10.1093/oep/gpq002

Greenhaus, J. H., Parasuraman, S., \& Wormley, W. M. (1990). Effects of race on organizational experiences, job performance evaluations, and career outcomes. Academy of management Journal, 33(1), 64-86. https://doi.org/10.5465/256352

Holland, J. L. (1997). Making Vocational Choices: A Theory of Vocational Personalities and Work Environments (3rd ed.). Psychological Assessment Resources, Odessa, Fl.

Khan, L. J., \& Morrow, P. C. (1991). Objective and subjective underemployment relationships to job satisfaction. Journal of Business Research, 22, 211-218. https://doi.org/10.1016/0148-2963(91)90002-f

Kril, Z., Geva, A., \& Aloni, T. (2016). Not all degrees are created equal: examination of wage premium from obtaining higher education, as a function of field of study. Work paper, Chief Economist's Department, Ministry of Finance.

Leana, C. R., Feldman, D. C., \& Tan, G. Y. (1998). Predictors of coping behavior after a layoff. Journal of Organizational Behavior,

19 85-97. https://doi.org/10.1002/(sici)1099-1379(199801)19:1<85::aid-job838>3.0.co;2-y

Leny, M. (2009). Components of Organizational Identity, Workplace Satisfaction and Turnover Intentions. (Department of Sociology and Anthropology Master's Thesis). Bar-Ilan University, Israel.

Lipiner, I., Rosenfeld, D., \& Zussman, N. (2020). Over-education and Mismatch between Occupation and Major Subject among University and College Graduates. Bank of Israel: Jerusalem.

Littman-Ovadia, H., \& Davidovich, N. (2008). Satisfaction, Commitment, Job Success and Personal Welfare amidst Ariel University Center of Samaria Alumni. People and Work, 1, 269-282.

McKee-Ryan, F. M., \& Harvey, J. (2011). "I have a job, but . . .": A review of underemployment. Journal of Management, 37(4), 962-996. https://doi.org/10.1177/0149206311398134

McKee-Ryan, F. M., Virick, M., Prussia, G. E., Harvey, J., \& Lilly, J. D. (2009). Life after the layoff: Getting a job worth keeping. Journal of Organizational Behavior, 30(4), 561-580. https://doi.org/10.1002/job.566

Morck, R., Yavuz, M. D., \& Yeung, B. (2011). Banking system control, capital allocation and economy performance. Journal of Financial Economics, 100(2), 264-283. https://doi.org/10.3386/w15575

Nathan, L. (2009). The Relationship between the Engagement Pattern of a Team Manager with its Organizational Culture and Performance. (School of Business Administration PhD Thesis). Bar-Ilan University, Israel.

Ng, T. W. H., Eby, L. T., Sorensen, K. L., \& Feldman, D. C. (2005). Predictors of objective and subjective career success: A meta-analysis. Personnel Psychology, 58, 
https://doi.org/10.1111/j.1744-6570.2005.00515.x

Nordin, M., Persson, I., \& Rooth, D. O. (2010). Education-occupation mismatch: is there an income penalty? Economics of Education Review, 29, 1047-1059. https://doi.org/10.1016/j.econedurev.2010.05.005

OECD. (2017). Education at a Glance 2017: OECD indicators. OECD Publishing, Paris.

Ordine, P., \& Rose, G. (2011). Inefficient self-selection into education and wage inequality. Economics of Education Review, 30(4), 582-597. https://doi.org/10.1016/j.econedurev.2011.03.007

Price, J. L. (1997). Handbook of organizational measurement. International Journal of Manpower, 18(4/5/6), 303-558. https://doi.org/10.4135/9781412984386.n85

Ren, H., Bolino, M. C., Shaffer, M. A., \& Kraimer, M. L. (2013). The influence of job demands and resources on repatriate career satisfaction: A relative deprivation perspective. Journal of World Business, 48, 149-159. https://doi.org/10.1016/j.jwb.2012.06.015

Robst, J. (2007). Education and job match: the relatedness of college major and work. Economics of Education Review, 26, 397-407. https://doi.org/10.1016/j.econedurev.2006.08.003

Romanov, D., Tur-Sinai, A., \& Eizman, G. (2017). Overeducation, job mobility and earnings mobility among holders of first degrees. Applied Economics, 49(26), 2563-2578. https://doi.org/10.2139/ssrn.1303626

Rubin, M. (2010). Workplace Satisfaction: Predictive Elements. (Department of Psychology Master's Thesis), Tel-Aviv University, Israel.

Stumpf, S. A., \& Taymon, W. G. (2012). The effects of objective career success on subsequent subjective career success. Journal of Vocational Behavior, 81(3), 345-353. https://doi.org/10.1016/j.jvb.2012.09.001

Thompson, K. W., Shea, T. H., Sikora, D. M., Perrewe, P. L., \& Ferris, G. R. (2013). Rethinking underemployment and over-qualification in organizations: The not so ugly truth. Business Horizons, 56, 113-121. https://doi.org/10.1016/j.bushor.2012.09.009

Van Dyne, L., \& LePine, J. A. (1998). Helping and voice extra-role behaviors: Evidence of construct and predictive validity. Academy of Management journal, 41(1), 108-119. https://doi.org/10.2307/256902

Verbruggen, M., van Emmerik, H., Van Gils, A., Meng, C., \& de Grip, A. (2015). Does early-career underemployment impact future career success? A path dependency perspective. Journal of Vocational Behavior, 90, 101-110. https://doi.org/10.26481/umaror.2015007

Watt, J. D., \& Hargis, M. B. (2010). Boredom proneness: Its relationship with subjective underemployment, perceived organizational support and job performance. Journal of Business Psychology, 25, 163-174. https://doi.org/10.1007/s10869-009-9138-9

Yucel, I. (2012). Examining the relationships among job satisfaction, organizational commitment, and turnover intention: An empirical study. International Journal of Business and Management, 7(20), 44-58. https://doi.org/10.5539/ijbm.v7n20p44.

\section{Copyrights}

Copyright for this article is retained by the author(s), with first publication rights granted to the journal.

This is an open-access article distributed under the terms and conditions of the Creative Commons Attribution license (http://creativecommons.org/licenses/by/4.0/). 